\title{
PENINGKATAN KEMAMPUAN BERPIKIR KRITIS MELALUI PENGGUNAAN STRATEGI ACTIVE SHARING KNOWLEDGE UPAYA MEMPERSIAPKAN GENERASI ABAD 21
}

\author{
(Improving Critical Thingking Ability through the Use of Achtive Sharing Knowledge \\ Strategy to Prepare $21^{\text {st }}$ Century Generation) \\ Sepita Ferazona*) \\ E-mail : sepitafera@gmail.com
}

${ }^{*}$ Dosen Pendidikan Biologi FKIP UIR

\begin{abstract}
.
This study aims to look at the Critical Thinking Ability through the Use of Active Sharing Knowledge Strategies in efforts to prepare the 21st century generation of Material Excretion Systems. This research was conducted in April-July 2018/2019 Academic Year, in the Riau Islamic University, Faculty of Teacher Training and Education in Biology Study Program. The sample of this study consisted of one class, the determination of the sample by using purposive sampling technique. This type of research is a survey research with a qualitative approach. The method used in this research is experiment, which aims to find out a symptom or influence that arises, as a result of the existence of certain treatments. The data obtained were analyzed using quantitative data analysis techniques. The data obtained is the ability of students' critical thinking. The assessment of critical thinking abilities is carried out in accordance with the six indicators of critical thinking, namely: 1) Focus (focus), 2) Arguments (Reason), 3) Conclusions (inferences), 4) Situations, 5) Clarity (Clarity), 6) Advanced Overview (Overview). The results showed that of the 17 critical thinking questions tested obtained different presentations. $45 \%$ of the students' answers in the categories are very good and 55\% are in the good categories. This proves that students' thinking on excretion system material.
\end{abstract}

Kata Kunci: Active Sharing Knowledge Strategy, critical thingking, Respiration system

\section{PENDAHULUAN}

Suyono dan Harianto dalam Afrianto (2015: 1), mengungkapkan bahwa salah satu tujuan pendidikan adalah untuk membentuk manusia yang memiliki kecakapan hidup. Kecakapan hidup adalah kecakapan yang dimiliki seseorang untuk berani menghadapi problematika kehidupan dengan wajar tanpa merasa tertekan kemudian secara proaktif dan kreatif mencari serta menemukan solusi untuk mengatasinya. Secara umum, kecakapan hidup diklasifikasikan menjadi empat jenis, yaitu: 1) Kecakapan personal yang mencakup kecapakan mengenal diri dan kecakapan berpikir; 2) Kecakapan sosial; 3) Kecakapan akademik; dan 4) Kecakapan vokasional.

Pembelajaran aktif adalah belajar yang memperbanyak aktivitas dalam mengakses berbagai informasi dari berbagai sumber, untuk dibahas dalam proses pembelajaran dalam kelas, sehingga memperoleh berbagai pengalaman yang tidak saja menambah pengetahuan, tapi juga kemampuan analisis dan sintesis (Rosyada dalam Nurhayati, 2008).

Pembelajaran abad 21 secara sederhana diartikan sebagai pembelajaran yang memberikan kecakapan abad 21 
kepada peserta didik, yaitu 4C yang meliputi: (1) Communication (2) Collaboration, (3) Critical Thinking and problem solving, dan (4) Creative and Innovative. Berdasarkan Taksonomi Bloom yang telah direvisi oleh Krathwoll dan Anderson, kemampuan yang perlu dicapai siswa bukan hanya LOTS (Lower Order Thinking Skills) yaitu C1 (mengetahui) dan C-2 (memahami), MOTS (Middle Order Thinking Skills) yaitu C3 (mengaplikasikan) dan C-4 (mengalisis), tetapi juga harus ada peningkatan sampai HOTS (Higher Order Thinking Skills), yaitu C-5 (mengevaluasi), dan C-6 (mengkreasi).

Kehidupan di abad ke-21 menuntut berbagai keterampilan yang harus dikuasai seseorang, sehingga diharapkan pendidikan dapat mempersiapkan siswa untuk menguasai berbagai keterampilan tersebut agar menjadi pribadi yang sukses dalam hidup. Keterampilan-keterampilan penting di abad ke-21 masih relevan dengan empat pilar kehidupan yang mencakup learning to know, learning to do, learning to be dan learning to live together. Empat prinsip tersebut masingmasing mengandung keterampilan khusus yang perlu diberdayakan dalam kegiatan belajar, seperti keterampilan berpikir kritis, pemecahan masalah, metakognisi, keterampilan berkomunikasi, berkolaborasi, inovasi dan kreasi, literasi informasi, dan berbagai keterampilan lainnya (Zubaidah, 2016).

Saat ini kualitas sumber daya manusia di Indonesia masih berada dibawah sumber daya Negara lainnya. Bahkan, meski mengalami kemajuan Indonesia tetap berada pada peringkat rendah diwilayah Asia Tenggara. Berdasarkan data yang dikeluarkan oleh UNDP (United Nations Development Programme) tahun 2015, HDI (Human Development Index) yang mengukur beberapa aspek sumber daya manusia antar negara, Indonesia berada pada peringkat Ke 110 dari 188 Negara, dibawah Singapura yang menempati peringkat Ke11, Brunei Darrussalam di peringkat Ke31, Thailand di peringkat Ke-93 dan diatas sedikit dari Filippina yang menempati Peringkat Ke-115(Wardah, 2015).

Dengan melihat permasalahan diatas, pembenahan yang dapat dilakukan dengan menggunakan berbagai macam cara, yaitu mengajarkan dan mengembangkan kemampuan berpikir kritis sebab kemampuan berpikir kritis dipandang sebagai sesuatu yang sangat penting untuk dikembangkan agar mahasiswa mampu dan terbiasa menghadapi permasalahan di sekitarnya. Menurut Cabera dalam (Husnidar dkk, 2014: 72) penguasaan kemampuan berpikir kritis tidak cukup disajikan sebagai tujuan pendidikan semata, tetapi juga sebagai proses fundamental yang memungkinkan mahasiswa untuk mengatasi berbagai permasalahan masa mendatang di lingkungannya. Untuk itu dalam proses belajar mengajar tidak boleh mengabaikan penguasaan kemampuan berpikir siswa (Husnidar dkk, 2014: 72)., Peran guru dalam melaksanakan pembelajaran abad ke-21 sangat penting dalam mewujudkan masa depan anak bangsa yang lebih baik.

Penelitian yang sudah dilakukan pada materi yang sama dengan Analisis Kemampuan Berpikir Tingkat Tinggi (Higher Order Thinking Skills) Mahasiswa Pada Mata Kuliah Anatomi Fisiologi Manusia Lanjut Materi Sistem Ekskresi. dengan capaian hasil dengan enam indikator berpikir kritis yaitu: 1) Fokus (fokus), 2) Argumen (Reason), 3) Kesimpulan (inference), 4) Situasi (Situation), 5) Kejelasan (Clarity), 6) Tinjauan Lanjut (Overview). Hasil Penelitian menunjukkan dari 12 soal berpikir kritis yang diuji memperoleh 
presentasi yang berbeda. Rata-rata tertinggi dengan perolehan skor 5 pada soal nomor 1 dengan presentasi $61,67 \%$ dan perolehan skor.

\section{METODOLOGI PENELITIAN}

Penelitian ini dilakukan pada bulan April - Juli Tahun Ajaran 2018/2019 di universitas Islam Riau, Fakultas Keguruan dan Ilmu Kependidikan Prodi Biologi. Sampel penelitian ini terdiri dari 41 mahasiswa Jenis penelitian ini adalah penelitian survei dengan pendekatan deskriptif kualitatif. Data yang diperoleh dianalisis dengan menggunakan teknik analisis data kuantitatif. Data yang diperoleh ialah kemampuan berpikir kritis siswa.

Penilaian kemampuan berpikir kritis dilakukan sesuai dengan enam indikator berpikir kritis yaitu: 1) Fokus (fokus), 2) Argumen (Reason), 3) Kesimpulan (inference), 4) Situasi (Situation), 5) Kejelasan (Clarity), 6) Tinjauan Lanjut (Overview).

Pemberian skor berpikir kritis dalam soal-soal disesuaikan dengan penskoran menurut Stiggins, (1994: 153). Tabel penskoran kemapuan berpikir kritis dapat dilihat pada Tabel 1 di bawah ini: 
Tabel 1. Penskoran Kemampuan Berpikir Kritis

\begin{tabular}{|c|c|l|}
\hline Kategori & Skor & \multicolumn{1}{|c|}{ Indikator penilaian } \\
\hline Skor tinggi & 5 & $\begin{array}{l}\text { Jawaban yang diberikan jelas, fokus dan akurat. Butir- } \\
\text { butir yang relevan dikemukakan (berhubungan dengan } \\
\text { pertanyaan pada soal) untuk mendukung jawaban yang } \\
\text { diberikan. Hubunan antara jawaban dengan soal } \\
\text { tergambar secara jelas }\end{array}$ \\
\hline Skor sedang & 3 & $\begin{array}{l}\text { Jawaban yang diberikan jelas dan cukup fokus, namun } \\
\text { kurang lengkap. Contoh-contoh yang diberikan terbatas. } \\
\text { Keterkaitan antara jawaban dengan soal kurang jelas. }\end{array}$ \\
\hline Skor rendah & 1 & $\begin{array}{l}\text { Jawaban yang diberikan kurang sesuai dengan apa yang } \\
\text { dimaksudkan dalam soal, berisi informasi yang tidak } \\
\text { akurat atau menunjukkan kurangnya penguasaan terhadap } \\
\text { materi. Butir-butir yang diberikan tidak jelas, tidak } \\
\text { memberikan contoh yang mendukung }\end{array}$ \\
\hline & 0 & Tidak ada jawaban \\
\hline
\end{tabular}

Sumber: Stiggins, (1994:153)

Tabel 4. Interpretasi Kategori Kemampuan Berpikir Kritis

\begin{tabular}{|l|l|}
\hline Interpretasi & Katagori \\
\hline $81,26-100$ & Sangat Tinggi \\
\hline $71,51-81,25$ & Tinggi \\
\hline $62,51-71,50$ & Sedang \\
\hline $43,77-62,50$ & Rendah \\
\hline $0-43,75$ & Sangat Rendah \\
\hline
\end{tabular}

(Setyowati,2011) 


\section{HASIL DAN PEMBAHASAN}

Data kemampuan berpikir kritis mahasiswa diperoleh dari tes uraian, yang dijabarkan pada Tabel 1 di bawah ini.

\begin{tabular}{|l|l|l|}
\hline No & $\begin{array}{l}\text { Katagori } \\
\text { (Kemampuan } \\
\text { Berpikir Kritis) }\end{array}$ & $\begin{array}{l}\text { Jumlah } \\
\text { Mahasiswa }\end{array}$ \\
\hline 1 & Sangat Tinggi & 18 \\
\hline 2 & Tinggi & 22 \\
\hline 3 & Sedang & - \\
\hline 4 & Rendah & - \\
\hline 5 & Sangat Rendah & \\
\hline
\end{tabular}

Tabel diatas menjelaskan hasil kemampuan berpikir kritis melalui penggunaan strategi active sharing knowledge, jumlah mahasiswa yang memperoleh katagori sangat baik 18 mahasiswa sedangkan yang memperoleh katagori baik 22 mahasiswa. Tidak ada perolehan untuk katagori sedang, rendah dan sangat rendah. Persentase hasil kemampuan berpikir kritis melalui penggunaan strategi active sharing knowledge setiap katagori dapat dilihat Gambar 1.

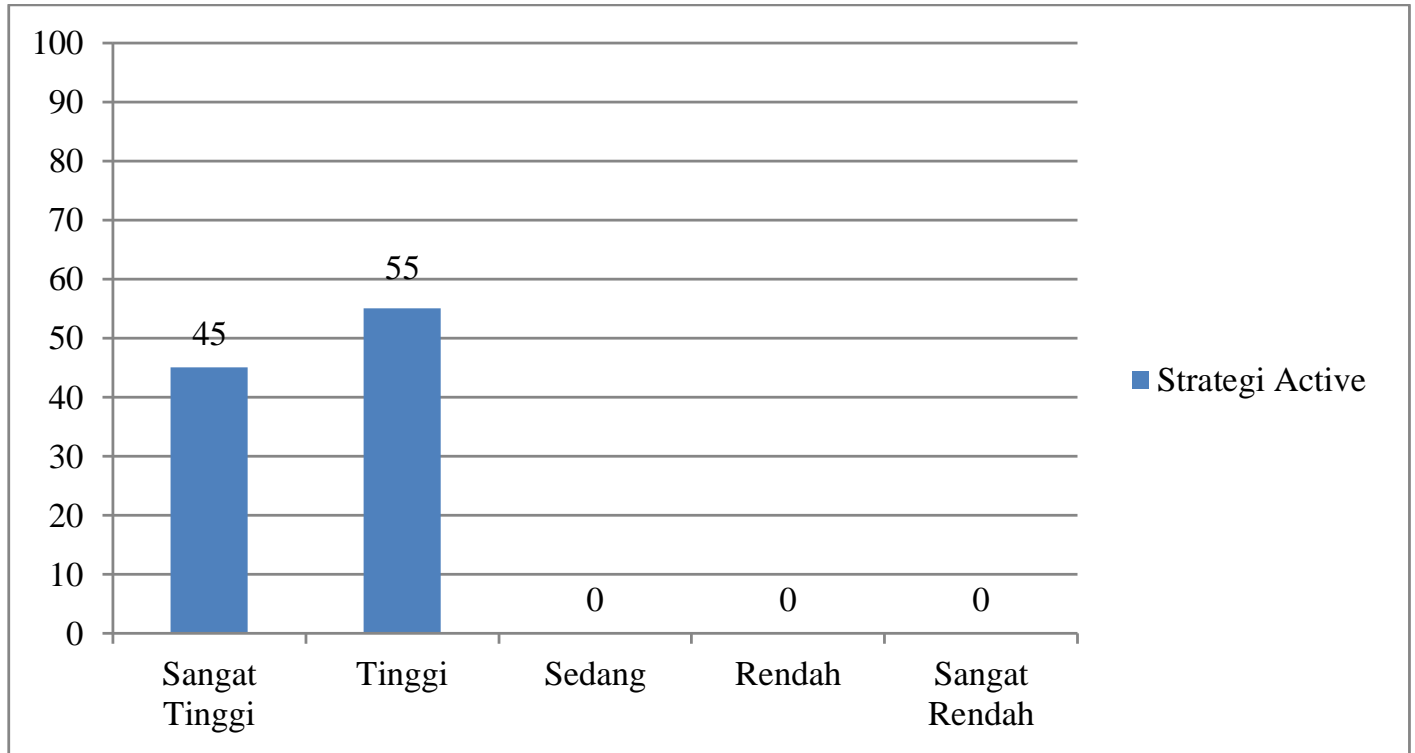

Gambar 1: persentase hasil jumlah mahasiswa dalam menjawab penggunaan strategi active sharing knowledge

Gambar 1 diatas menjelaskan persentase hasil jumlah mahasiswa dalam menjawab penggunaan strategi active sharing knowledge setiap katagori. Dari $100 \%$ jumlah siswa, $45 \%$ mahasiswa memperoleh katagori sangat tinggi dan $55 \%$ mahasiswa memperoleh katagori tinggi. Tidak ada perolehan untuk katagori sedang, rendah dan sangat rendah.

\section{PEMBAHASAN}

Soal berpikir kritis yang sudah dikerjakan mahasiswa dengan penggunaan strategi active sharing 
knowledge menunjukkan katagori yang di peroleh yaitu sangat tinggi dan tinggi. Dengan jumlah 12 soal Pilihan Ganda dan 5 Soal Essay. Menunjukkan kemampuan berpikir kritis mahasiswa sudah baik. Sesuai pendapat Ennis (2001) ketika seseorang memiliki kemampuan berpikir kritis maka secara otomatis seseorang tersebut dapat bertahan dalam menyelesaikan permasalahan.

Pendapat Ennis (2001) setiap seseorang memiliki kemampuan berpikir kritis, maka ketika iru seseorang dapat menyelesaikan masalah dan dapat bertahan dalam permasalahan. tingkat berpikir rendah adalah keterampilan menghafal (recall thinking) yang terdiri atas keterampilan yang hampir otomatis atau refleksif. jadi siswa dengan tingkat berpikir paling rendah hanya sebatas pada kemampuan menghafal tanpa bisa memahami konsep dengan baik. selanjutnya adalah hanya sebatas memahami soal.

Anggareni dkk (2013) menyatakan untuk mengembangkan banyak hal yang bisa dilakukan untuk melatih berpikir kritis mahasiswa sering mempetanyakan fenomenafenomena mengeni materi yang dipelajari. Pengajar harus mampu menciptakan pembelajaran yang dapat mengikutsertakaan mahasiswa secara aktif dalam kegiatan pembelajaraan. hal ini penting agar terciptaa interaksi yang intensif antara siswa, guru dan materi pembelajaran serta memberikan peluang untuk melibatkan kemaampuan berpikir siswa, dengan demikian diharaapkan dapat meningkatkan kemampuan berpikir ktitisnya.

Hasil penelitian Alghafri \& Ismail (2014), menunjukkan bahwa ada perbedaan signifikan antara kelas yang dibelajarkan dengan mengembangkan kemampuan berpikir kritis dengan yang tidak. perbedaan ini tampak dalam aspek kelancaran berkomunikasi dan melakukan eksperimen. hal ini disebabkan lingkungan belajar siswa akan mempengaruhi gaya berpikirnya. siswa yang dibelajarkan dengan mengembangkan kemampuan berpikir kritis akan akan merasa bebas untuk mengembangkan lebih banyak ide, karena guru memberikan kesempatan menghasilkan ide-ide baru selama proses pembelajaran. kemampuan berpikir kritis berhubungan positif dengan hasil belajar kognitif. pernyataan ini didukung oleh Cano dan Maryinez (1991), yaitu biasanya siswa kemampuan berpikir kritisnya rendah akan diikuti oleh hasil belajar kognitif yang rendah pula.

\section{KESIMPULAN}

Hasil Penelitian menunjukkan dari 17 soal berpikir kritis yang diuji memperoleh presentasi yang berbeda. $45 \%$ jawaban mahasiswa pada katagori sangat baik dan $55 \%$ berada pada katagori baik. Ini membuktikan berpikir mahasiswa pada materi sistem ekskresi sudah baik. 


\section{DAFTAR PUSTAKA}

Afrianto, F. (2016). Penerapan Model Pembelajaran Problem Based Learning pada Materi Hukum Newton untuk Meningkatkan Kemampuan Berpikir Kritis Siswa Kelas X SMA Negeri PLUS Provinsi Riau. Skripsi. Universitas Riau. Pekanbaru.

Stiggins, R. J, (1994). StudentCentered Classroom Assessment. New York: Merrill, an imprint of Macmillan College Publhing Company

Amri, S., \& Ahmadi I, K. (2010). Proses Pembelajaran Inovatif dan Kreatif di dalam Kelas. Jakarta: PT Prestasi Pustakaraya.

Ayuningrum, D., \& Susilowati. (2015).

Pengaruh Model Problem Based Learning Terhadap Keterampilan Berpikir Kritis Siswa Sma Pada Materi Protista. Jurnal Pendidikan IPA Unnes. (Nomor 2 Tahun 2015). Hlm. 1-2.

Fakhriyah, F. (2014). Penerapan Problem Based Learning Dalam Upaya Mengembangkan Kemampuan Berpikir Kritis Mahasiswa. Jurnal Pendidikan IPA Unnes. (Nomor 1 Tahun 2014). Hlm. 1-2.

Fisher, A. (2008). Berpikir Kritis: Sebuah Pengantar. (Alih Bahasa: Benyamin Hadinata). Jakarta: Erlangga.

Hanafiah, N. \& Cucu, S. (2010). Konsep Strategi Pembelajaran. Bandung: Refika Aditama.
Hamdani, M.A. (2011). Strategi Belajar Mengajar. Bandung: CV Pustaka Setia.

Inch, E. S. et al (2006). Critical Thingking and Communication The Use of Reason in Argument. Edisi 5. Wasington.

King, et al. (2000). Higher Order Thinking Skills. Assessment Evaluation Educational Services Program. [Online]. Tersedia: http://www.cala.fsu.edu. [20 Februari 2017].

Sanjaya, W. (2013). Penelitian Pendidikan: Jenis, Metode, dan Prosedur. Jakarta: Kencana.

Sari, N.K. (2014). Sikap Ilmiah dan Metode Imiah. Online. Tersedia di http://nuriithaa.blogspot.co.id/2014/03/sikapilmiah-dan-metode-ilmiah.html, (Diakses 13 Juli 2016)

Sudjana, N. (2005). Metoda Statistika. Bandung: Tarsito.

Sugiyono. (2010). Metode Penelitian Pendidikan Kuantitatif, Kualitatif, dan $R \& D$. Bandung: Alfabeta.

Suryabrata, S. (2010). Psikologi Pendidikan. Jakarta: PT Rajagrafindo Persada.

Suryobroto, B. (2009). Proses Belajar Mengajar di Sekolah. Jakarta: PT Rineka Cipta.

Trianto. (2010). Model-model Pembelajaran Terpadu. Jakarta: Bumi Aksara. 